\title{
"Ordenar la provincia". Sobre el carisma de Néstor Kirchner en Santa Cruz (1991-1996)
}

\section{Pamela Sosa*}

Perfiles Latinoamericanos, 26(51)

2018 | pp. 37-61

DOI: $10.18504 / \mathrm{pl} 2651-002-2018$

\section{Resumen}

En este artículo se reconstruye una de las principales estrategias de representación y fuente de poder del liderazgo de Néstor Kirchner en la provincia de Santa Cruz, Argentina, entre 1991 y 1996: su consolidación de "garante del orden y la estabilidad". En segundo lugar, se analizan las condiciones sociales que explican el éxito de esta estrategia de representación, en particular su afinidad con un conjunto de atributos sociales de la provincia definidos como parte de la "cultura del sufrimiento" y la capacidad del Frente para la Victoria como organización que encarnaba valores análogos a los comprendidos en la misma. Para cumplir con el objetivo, se utilizaron entrevistas semiestructuradas y análisis de archivos periodísticos. El trabajo es un antecedente en el análisis de las formas de construcción de poder del Frente para la Victoria en sus orígenes, a principios de la década de 1990, en su experiencia previa al acceso al gobierno nacional en 2003 .

\begin{abstract}
In this article, we reconstruct one of the main representation strategies and sources of power for Néstor Kichner's leadership in Santa Cruz, Argentina between 1991 and 1996: his consolidation as a "warrantor of order and stability". In second stance, we will analyze the social conditions that explain the success of this strategy of representation. Mainly, its affinity with a set of social attributes of the province defined as part of the "culture of suffering" and the ability of the Frente para la Victoria as an organization to embody analog values. We use for the making of this article mostly semi-structured interviews and analysis of journalistic archives. This work is a valuable study on the forms of power construction of the Frente para la Victoria since its origins, in the early 1990, a previous experience to its access of the national government in 2003.
\end{abstract}

Palabras clave: Néstor Kirchner, orden y disciplina, conflicto político, cultura política, Frente para la Victoria, peronismo, Santa Cruz.

Keywords: Néstor Kirchner, order and discipline, political conflict, political culture, Frente para la Victoria, peronismo, Santa Cruz.

\footnotetext{
* Doctora en Ciencias Sociales (UBA). Becaria Posdoctoral de cOnICET/unL | pamesosa@hotmail.com
} 


\section{Introducción}

E

Frente para la Victoria Santacruceña (Fvs), organización liderada por Néstor Kirchner, ocupó la gobernación de la provincia argentina de Santa Cruz en 1991 donde ejerció el poder hasta 2003, luego de dos reelecciones del cargo de gobernador (1995 y 1999) y dos reformas constitucionales (1994 y 1999). Para 2003, esa organización se conformó en una fuerza política nacional que se denominó Frente para la Victoria (FPV), la cual accedió al gobierno federal el cual mantuvo después de dos reelecciones — 2007 y 2011- y ocupar los principales cargos de la política nacional. De la misma manera que en su trayectoria nacional, el Fvs asumió la gobernación con un escaso caudal político y un déficit de legitimidad inicial (Aboy, 2005; Rinesi, Vommaro \& Muraca, 2010; Sidicaro, 2011; Novaro, 2011). Efectivamente, si a la instancia nacional había llegado con el $22.24 \%$ de votos, la gobernación de Santa Cruz la había obtenido con solo el 33\% en el marco de una alianza con el MRP (Movimiento Renovador Peronista). Este déficit de legitimidad inicial, vinculado a la crisis de los partidos políticos en Santa Cruz —en especial del Partido Justicialistaobligó al FVs a buscar caminos para conseguir crédito político por fuera de las estructuras y estrategias de representación partidarias. El propósito de este artículo es analizar la estrategia de representación y fuente central del carisma de Néstor Kirchner en la provincia de Santa Cruz en este contexto, esto es: su capacidad de generar "orden". ${ }^{1}$

Este artículo constituye un doble aporte a los estudios políticos. En primer lugar, significa un antecedente en la investigación acerca del Frente para la Victoria en la provincia de Santa Cruz, una etapa de su desarrollo político poco explorada (Vilaboa \& Bona, 2016). En segundo, el trabajo propone complementar las

1 Uno de los símbolos más importantes de la transformación que vivió la Argentina en las últimas décadas del siglo xx fue la irrupción en la política de líderes fuertes que poseían relaciones distantes con las organizaciones, las bases y las tradiciones de las fuerzas a las que representaban. Denominados muchas veces como extrapartidarios u outsiders de la política, estos líderes tenían como denominador común establecer proyectos, centrarse en liderazgos personales, y ser autónomos respecto de las dinámicas, actores, grupos e instituciones que hasta entonces habían organizado y condicionado las relaciones de poder. Sobre estos liderazgos y sus características, puede consultarse Novaro (1994), Cheresky (2004), Fabbrini (2009) y Sidicaro (2011). Carlos Saúl Menem (1989-1999), a nivel nacional; Carlos Reutemann (1991-1995; 1999-2003), en la provincia de Santa Fe; Néstor Kirchner (1991-2003), en Santa Cruz; Ramón "Palito" Ortega (1991-1995), en Tucumán; Antonio Bussi (1995-1999), en Tucumán, y Jorge Escobar (19911992; 1994-1999), en San Juan, entre otros, formaron parte de ese grupo que se consolidó, con más o menos fortuna, y se mantuvo en el poder por extensos periodos de tiempo constituyéndose en verdaderos bastiones del poder político en sus territorios. Para mayor desarrollo sobre las particularidades de estos dirigentes, véase Novaro (1994), Isla (2000), Lascurain (2011), Sosa (2011) y Rodrigo (2013). 
interpretaciones sobre los fenómenos de la representación y la construcción de liderazgos en contextos de crisis de legitimidad de las organizaciones políticas, especialmente a partir de la década de 1990. Así, mientras la fuente del poder carismático en este contexto político ha generado tres interpretaciones sobre diferentes casos en Argentina, pero con una clara presencia en las matrices interpretativas de los fenómenos de liderazgo en Latinoamérica, el carisma de los líderes se ha definido como el efecto de la relación que los nuevos líderes establecen con la "opinión pública" (Novaro, 1994; Cheresky \& Pousadela, 2004; Abal, 2004; Rodríguez, 2006; Mauro, 2007). Dicho de otra manera, por la capacidad de aquellos para sortear y dominar situaciones de crisis, generalmente por medio de criterios ejecutivistas y discrecionales que eluden el control institucional y la participación democrática (Novaro, 1994; O’Donnell, 1997; Bosoer \& Leiras, 1999; Pucciarelli, 2002; Quiroga, 2005); o bien, a partir de su construcción de la escenificación de la relación amigo-enemigo y su correlato en identidades políticas mediante esa forma de representación, tesis que han sostenido los estudios de los "nuevos" populismos (Aboy, 2005; Rinesi, Vommaro \& Muraca, 2010; Rinesi, 2007; Yabkowski, 2012). Partiendo de otra matriz teórico-interpretativa, ${ }^{2}$ este artículo propone una mirada complementaria sobre las fuentes del poder carismático de Néstor Kirchner, en la que cobran relevancia los atributos culturales de la sociedad en la que se fundó.

En tal sentido, este análisis puede leerse como un caso de construcción de liderazgo en el que existe una interpretación y representación de la "opinión pública” propias de la coyuntura histórica de principios de la década de 1990, cuando la demanda de estabilidad y superación de la crisis económica y social fue parte central de la agenda pública. Pero también puede leerse como un caso típico de liderazgo decisionista en el que la capacidad ejecutiva de gobernar la crisis brindó sustento de legitimidad al carisma de Néstor Kirchner. Por último, el caso además permite ver la instauración de la lógica amigo-enemigo como una forma de movilizar la opinión y la representación. Sin embargo, el aporte esencial consiste en analizar y mostrar la convergencia de estas interpretaciones, las cuales son aplicables a la mayoría de los liderazgos de gobiernos provinciales que fueron parte de la coyuntura política argentina de la época, con la particularidad

2 Se asume el concepto de liderazgo como el producto de una relación de representación. Para el análisis de las estrategias de esta última, se parte de los supuestos teóricos de Bourdieu (1993), Lagroyé (1994), Offerlé (2004) y Gaxie (2004), quienes la han definido como una relación doblemente condicionada, tanto por las posiciones y estrategias de los actores que forman parte del campo político y que producen e imponen, en el marco de la lucha, principios de visión y división del mundo social, como por las relaciones que estos actores, en pos de mejorar sus posiciones, establecen con los actores externos al campo político o los grupos que mediante el trabajo de representación los actores políticos hacen existir y movilizan. Desde este punto de vista, el carisma es parte de esta doble relación. 
de la política y la sociedad santacruceña. Lo que el artículo pretende visibilizar es la forma local de llevar a cabo un conjunto de políticas que también se aplicaron en el resto del país con formatos similares, pero atendiendo a los rasgos culturales específicos de esa sociedad. Efectivamente, el trabajo muestra, y este es quizá su mayor aporte, que "salirse" del marco de las instituciones de representación o control, como el parlamento, los partidos políticos o cualquier instancia semejante, puede ser una forma de encarnar valores más afines con la sociedad — como en este caso, expresar a nivel político el poder de "garantizar orden"-, estrategia que presentó una gran proximidad con la cultura local. El análisis invita a adentrarse en los universos provinciales para rastrear cómo los fenómenos de carácter nacional —el surgimiento de liderazgos personalistas o ejecutivistasse anclan en relaciones de representación y legitimación solo comprensibles en el marco de los climas sociales y culturales locales. ${ }^{3}$

Para cumplir estos objetivos se utilizaron datos extraídos de un corpus de 35 entrevistas semiestructuradas hechas por la autora de este artículo en marzo y noviembre de 2009 y quince entrevistas de archivos periodísticos realizadas en 1997. Se utilizan también diarios y revistas provinciales, documentos parlamentarios, archivos partidarios, decretos de necesidad y urgencia y un conjunto de leyes vinculadas a los procesos de ajuste económico y reforma del Estado, todos referenciados en el desarrollo de este texto. Estas fuentes permitieron reconstruir el estado del campo político de fines y comienzos de la década de 1990 y las principales medidas - y sus fundamentos - tomadas en ese periodo. Un recurso más ha sido una base de datos de elaboración propia que versa sobre la trayectoria migratoria, educativa, socioeconómica y partidaria de las élites políticas de Santa Cruz entre 1973 y 1999. Finalmente, para el análisis de las características sociales y culturales de la provincia de Santa Cruz se han usado diversas fuentes primarias como los datos del censo nacional de población y vivienda, y secundarias como Cuadra (2000), Rivas (2004), Carbonetti, Peretti \& Tarabella (S/R) y Sosa (2014), entre otras.

\section{"Ordenar el caos". La imagen de autoridad como capital político}

Como expresa la marca "Frente para la Victoria Santacruceña”, Santa Cruz fue la referencia que esta organización eligió y pretendió representar en la búsqueda

3 En otras investigaciones (Sosa, 2014), hemos desarrollado lo que consideramos tres estrategias de construcción de liderazgo de Néstor Kirchner en Santa Cruz: su condición de "defensor" de los intereses de Santa Cruz ante el poder central o nacional, su "capacidad de hacer y de concretar" y su autoridad para generar condiciones de "orden" en la provincia. En este trabajo nos ocuparemos específicamente de esta última. 
de un grupo que le brindara un sustento de legitimidad. En este marco nació un conjunto de símbolos políticos que expresaron fuertemente las estrategias de representación del fvs: "Por todos. Por una nueva Santa Cruz" y el más tradicional "Primero Santa Cruz". Sin embargo, el fvs no era la única marca política que se arrogaba la representación de los santacruceńos. En 1991 compitieron por dicha gobernación el Movimiento por Santa Cruz (Moposa), un sublema de la Unión Cívica Radical (UCR) que se autonominó por "Santa Cruz" y el sublema del Partido Justicialista (PJ) que compitió contra el FVs, esto es, el Movimiento Federal por Santa Cruz (Mofesa). ${ }^{4}$ En 1995, el más importante rival del Fvs, fue el conglomerado de diez partidos Encuentro Santacruceño que se formó para competir con aquel grupo político. La ausencia de diferencias grupales internas significativas y acentuadas para representar, una característica del campo político local de la provincia durante todo el siglo xx, fomentaba la estrategia de representación que interpelaba a todo el cuerpo social con la nominación de "santacruceńos". 5 A esto se sumaba, en el contexto de ascenso del fvs al iniciar la década de 1990, el debilitamiento de los grupos vinculado a la erosión de las bases sociales de representación de los partidos políticos y gremios en la provincia de Santa Cruz, fenómeno que posiblemente potenciaba una estrategia "atrápalo todo". "Sin embargo, como veremos, representar a los "santacruceños"

4 Datos del Ministerio del Interior de la Argentina, recuperados de http://www.mininterior.gov.ar/

5 En Santa Cruz los grupos sociales considerados usualmente como bases de representación de los partidos tuvieron una permanente tendencia a la disgregación, centralmente, por su composición migratoria reciente, los permanentes flujos de ingreso y egreso de habitantes, la baja población y su radicación reciente. Por otro lado, el fuerte componente urbano de su población con un perfil de clase media amplia, no ofrecían a los partidos clivajes sociales acentuados para disputarse a través de sus ofertas políticas. En este contexto, el peronismo, el cual dominó la política provincial durante todo el siglo xx, agrupó bajo su representación un conjunto de clivajes que, por lo menos en la década de 1980, no representaban demarcaciones y fronteras grupales tan sólidas para ordenar y garantizar una oferta política tan ampliada. Por aquel entonces, representaba tanto a los NYCS (nacidos y criados) como a los vYQs (venidos y quedados), a ciudadanos del norte y del sur y del campo y la industria. Pese a que estos grupos podían presentar oposiciones de intereses, no fueron lo suficientemente fuertes para constituirse en un clivaje que posibilitara la representación de los distintos sectores sociales por distintas fuerzas políticas. En este marco, el peronismo avanzó en una estrategia de aglutinar intereses heterogéneos, la cual ya había sido utilizada en otros territorios provinciales.

6 La crisis del modelo de Estado interventor hacia fines de la década de 1980 y las políticas aplicadas durante la de 1990 afectaron fuertemente la composición de los grupos sociales en Santa Cruz. Los procesos inflacionarios, la flexibilización laboral y la desocupación tuvieron fuertes impactos sobre una sociedad que poseía una dinámica social que limitaba la consolidación de los lazos sociales, producto de su condición de provincia de paso y su escasa población. El mayor indicador de la desestructuración fue el gran éxodo que afectó a la región, cuando importantes grupos de migrantes regresaron a sus pueblos de origen en el interior del país. Estas medidas afectaron la composición de los grupos que poseía la provincia hasta ese momento, la crisis de la producción ganadera e industrial debilitó las identidades y grupos de representación de los grupos conformados alrededor de esos sectores productivos y el éxodo matizó las fronteras entre los nacidos y criados y los venidos de otras provincias. 
no tuvo el mismo significado para todos los actores del campo político. En este apartado describiremos uno de los sentidos que tuvo representar los intereses de los santacruceños para el Fvs: generar "orden" en un contexto de "caos".

Uno de los mayores atributos que se imputa a Néstor Kirchner cuando se califica su condición de gobernante es que fue un "buen administrador". Múltiples entrevistas, aun de aquellos que no formaron parte del Fvs o del peronismo, sostienen el imaginario de esa provincia que define esa condición como el más importante rasgo de Néstor Kirchner. Sin embargo, como lo han comprobado otras fuentes de datos, esta virtud no estuvo vinculada directamente a las facultades técnicas en el ejercicio de la contabilidad de las cuentas públicas, sino a las tareas de reordenamiento y estabilización social, política y económica interna que acompañaron sus primeros años de gestión. Efectivamente, según el Informe Río, realizado entre julio y agosto de 1993 en la ciudad capital de la provincia, en el que se interrogaba a los encuestados por los atributos que más valoraban de la gestión del gobernador, la reorganización de la administración pública, el pago puntual de los salarios y el control de las huelgas aparecían como los ítems más valorados. ${ }^{7}$

Esta imagen se desprendía de las primeras medidas de gobierno del fvs las cuales se orientaron a "ordenar" la provincia. Pese a su fuerte contenido antipopular, lejos de restar imagen al gobierno, constituyeron una de las virtudes más grandes atribuidas a Kirchner. La siguiente entrevista muestra cómo aún sobreviven en el imaginario esas destrezas con las que se calificaba a aquel dirigente:

El Frente en la figura de Kirchner trajo responsabilidad, cosa que en ese momento la provincia estaba atravesando una situación bastante difícil. Fíjate que lo que pasó acá en el 2007, es menor a la situación que estábamos pasando nosotros en los noventa, en 89/90: acá los salarios no se pagaban, a la gente se le estaba adeudando hasta cinco meses de sueldo, a la administración pública en general, no se pagaba a comercio, proveedores, no se les aportaba a las obras sociales ni a la mutuales. Era un caos esto acá. Te imaginas una ciudad, una provincia que vive de lo que la administración pública puede llegar a dar, era todo un desastre. La actividad privada estaba muerta. No había clases [...] La verdad que fue una situación terrible. Y bueno lo que él en ese momento, cuando asume, plantea a la ciudadanía que había que dar un cambio de noventa grados porque no iba más el tema; había que terminar con un montón de gastos de la provincia que venía por favores, por cuestiones que venían de hacía muchos años en la provincia, el caso de viviendas, edificios alquilados. Muchos gastos que no se justificaban, pago de teléfonos. Entonces lo que hizo fue dar ese respiro a la provincia, ordenarla de tal

7 Véase, Panorama Político Semanal. (1992, 23 de septiembre). La Opinión Austral. p. 7. 
manera que la gente tome conciencia de lo que teníamos (Diputado provincial y funcionario del FVS. 60 ańos. Universitario incompleto. Entrevista propia. Marzo de 2009).

Para comprender el carácter positivo de la estrategia de construcción de orden, es necesario repasar el contexto social en el que se desplegó. Hacia fines de 1980 se encontraban suspendidos y atrasados los pagos del gobierno nacional a la provincia, institución de la que recibía sus mayores ingresos. Este hecho no sucedió en cualquier coyuntura. En ese entonces, Argentina se encontraba en un contexto de "hiperinflación", sin el cual no se comprende la intensidad de las crisis que afectaba a todos los territorios provinciales. En ese entonces, Santa Cruz dependía de las regalías que le liquidaba la petrolera estatal Yacimientos Petrolíferos Fiscales (YPF) y de la coparticipación federal de impuestos. Estas fuentes de ingreso estaban suspendidas y, por otro lado, desde 1981 YPF no entregaba los aportes correspondientes a los ingresos brutos - principal impuesto provincial— razón por la que mantenía, desde inicios de 1980, un juicio contra el Estado nacional por regalías mal liquidadas que ascendían a 480 millones de dólares. Como consecuencia de la crisis, existía un atraso en salarios y remuneraciones por setenta días y se habían suspendido los aportes a la Caja de Servicios Sociales de la provincia, a los gremios y a la Caja de Previsión Social. Una de las consecuencias más gráficas de la crisis, que se extendió de1988 a 1992, fue que en 1991 el sistema educativo estuvo inmovilizado gremialmente por noventa días. En este contexto asumió, a fines de 1991, el FVs y, luego de aplicar diversas medidas de ajuste, para agosto de 1992 la inestabilidad financiera provincial se había superado. La inflación había cesado, las cuentas públicas se habían equilibrado y la provincia recibía todos los ingresos adeudados, entre ellos el dinero del juicio por regalías mal liquidadas que equivalían a tres presupuestos anuales. El logro de este equilibrio no se logró de cualquier forma. Y es la manera en que se llevó a cabo lo que nos interesa mostrar y lo que sirvió de fundamento para el liderazgo de Kirchner.

Un repaso del perfil de las medidas implementadas, las metodologías y la imagen que comenzó a construir el Fvs ante la sociedad a principios de la década de 1990 permite apreciar que el conjunto de políticas y la performance desplegada en su implementación estuvieron orientadas a crear y aumentar los caudales de legitimidad de una fuerza política que había llegado al poder con un escaso capital electoral. A diferencia de lo que sucedió a nivel nacional en 1989, cuando Carlos Menem asumió la presidencia antes de lo previsto, como consecuencia de la crisis política del gobierno de Raúl Alfonsín, en Santa Cruz no hubo traspaso adelantado de gobierno. Ante la crisis generalizada en la que se encontraba la provincia antes y durante el proceso eleccionario de mayo de 
1991, el Frente para la Victoria esperó hasta último momento asumir la gobernación. El gobernador electo en 1987, Ricardo del Val, había sido destituido mediante juicio político en 1990 — juicio liderado por el Fvs- y lo habían sucedido dos gobernadores más que fueron soportando una crisis social que no cesaba. Todos los intentos de resolver autónomamente la crisis económica en una provincia sostenida estrictamente por flujos financieros nacionales habían sido estériles. En este marco, frente a los pedidos de las autoridades provinciales de implementar un traspaso adelantado, en un contexto en el que los gabinetes se disolvían constantemente, el Fvs sostuvo, durante los meses previos a su asunción, una actitud confrontativa con el gobierno saliente a quien denunció antes y después de la asunción por mal manejo de los fondos públicos. ${ }^{8}$ La lucha por la distinción y la construcción de una imagen de autoridad que le permitiera diferenciarse de los "gobiernos sin mando" y de las "corporaciones responsables de la crisis" comenzó meses previos a su ocupación del poder.

El Fvs fue afirmando sus diferencias con los distintos actores de representación, tanto políticos como sociales y se presentó ante la sociedad tanto como algo diferente de los "gobiernos anteriores responsables del caos", como enemigo de todos aquellos corresponsables de que la provincia se encontrara "en llamas". Las declaraciones del líder de la organización muestran cómo el nuevo gobierno, aun meses antes de asumir, se fue presentando ante la sociedad como la garantía del orden:

Será imposible pagar normalmente los sueldos y aguinaldos en diciembre. El cuadro financiero es tremendamente grave, ya no alcanzan los 12 millones de dólares para efectuar el ajuste de caja. Considero que hay absoluta irresponsabilidad en los tratamientos de paritarias y en el manejo de algunas empresas del Estado [...] Hay algunos que no quieren escuchar el veredicto de la gente que votó por el orden, por la normalización institucional, administrativa y financiera de la provincia [...] Lo que está pasando en la provincia es como el Titanic, se está hundiendo y algunos quieren seguir bailando en la cubierta, y esto no puede ser porque la situación de la provincia es extremadamente grave y extremadamente difícil ("Dr. Néstor Carlos Kirchner: Será imposible pagar normalmente los sueldos y aguinaldo en diciembre", La Opinión Austral, 22 de octubre de 1991: p. 9).

Con estos conceptos y bajo esta filosofía, el nuevo gobierno aplicó las primeras medidas políticas. En diciembre de 1991, dos días después de asumir,

8 Véase, Gobernador electo recibirá el gobierno el 10 de diciembre. (1991, 23 de octubre). La Opinión Austral; Dr. Néstor Carlos Kirchner: Será imposible pagar normalmente los sueldos y aguinaldo en diciembre. (1991, 22 de octubre). La Opinión Austral. 
declaró el estado de emergencia económica acompañado del Decreto de Necesidad y Urgencia ${ }^{9}$ que suspendió de inmediato los convenios colectivos de trabajo, subsidios, subvenciones y regímenes de promoción y de todos los regímenes legales de determinación de remuneraciones del personal dependiente de los tres poderes del Estado provincial. Con ese decreto, que nunca pasó por la legislatura provincial, se delegó en el Ejecutivo el establecimiento de las remuneraciones correspondientes a todo el personal que formara parte del Estado provincial. Frente a la evidencia de que, pese a la declaración de emergencia, el gobierno no podía afrontar la crisis, un mes después, el Fvs aplicó la segunda política de reordenamiento interno. Mediante un nuevo decreto ${ }^{10}$ declaró la suspensión de los pagos de los sueldos atrasados por parte del gobierno provincial. Declaró el no pago del mes de diciembre y el no pago de la segunda cuota del aguinaldo mientras que simultáneamente se produjo un descuento del $10 \%$ para los empleados que cobraran menos de 500 pesos y de un $15 \%$ para los que cobraran más de esa cifra. La medida, ordenada el 6 de enero de 1992, fue aplicada, como el primer Decreto de Necesidad y Urgencia en una "total soledad". ${ }^{11}$ La Cámara de Diputados se encontraba en receso, el Poder Judicial, en vísperas de la feria judicial, y buena parte de la población, especialmente en una provincia con un fuerte componente de migrantes internos, estaba de vacaciones. ${ }^{12}$

Finalmente, en julio del mismo año, el gobierno santacruceño aplicó una ulterior medida para resolver lo que para la época se denominaba el ausentismo y, paralelamente, la cuestión gremial. La política de presentismo fue un aumento salarial que tenía como contraprestación la asistencia perfecta orientada a terminar con el ausentismo y neutralizar el conflicto salarial. Implicó una bonificación especial para el personal docente y de sanidad que el gobierno empezó a otorgar por fuera del nominado salario básico. ${ }^{13}$ Como ha sido sostenido tanto por estudios sobre políticas educativas en las provincias argentinas (Rivas, 2004), como por dirigentes gremiales y políticos, esta medida implicaba indirectamente, dada la magnitud en el monto total del salario y el rigor de la norma (una sola inasistencia mensual implicaba la pérdida del "beneficio"), la suspensión del

9 Extraído de la copia del original del Decreto de Necesidad y Urgencia 139/91 facilitada por el Archivo de la Cámara de Diputados de la Provincia de Santa Cruz.

10 Extraído del texto original del Decreto de Necesidad y Urgencia 309/92.

11 El gobernador habló anoche al pueblo de la provincia. (1992, 7 de enero). La Opinión Austral.

12 Véase, Duras respuestas del sindicalismo local a las últimas medidas de gobierno. (1992, 10 de febrero). La Opinión Austral.

13 El valor del presentismo era del 25\% del total del salario bruto. Entre 1994 y 2000, el salario bruto de un maestro de grado con diez años de antigüedad era de 950 pesos y el salario de bolsillo de 818 . En este esquema de ingresos, el presentismo era 250 pesos por cargo (RIVAs, 2004). 
derecho a huelga. ${ }^{14}$ La medida tuvo la misma impronta que las anteriores, fue tomada omitiendo cualquier instancia de diálogo político que involucrara a los afectados. Más aún, replicó la misma estrategia de aplicarla en la ausencia física de los afectados y de sus representantes, a fines de julio de 1991, cuando la mayoría de los docentes estaba vacacionando por el receso invernal. ${ }^{15}$ Estas medidas formaron parte de la primera etapa de gobierno del Fvs y, por el modo en que se implementaron, fueron parte de la construcción de su capital político, de su credibilidad y de su crédito. Estas medidas y la filosofía política que las acompanó - que a primera vista podría pensarse que generan la pérdida de legitimidad de un gobierno - fueron parte del capital político del FVs como organización y de Kirchner como dirigente.

\section{Sobre las formas particulares de definir el "orden" en Santa Cruz}

Las medidas arriba descritas tuvieron en común dos rasgos que se debe destacar, sobre todo para luego comprender por qué aumentaron ellos el capital político del Fvs. En primer lugar, las medidas en cuestión se enfocaron en terminar con el conflicto interno $y$, en segundo, fueron establecidas prescindiendo de instancias de mediación y representación de intereses sociales. Ninguna de ellas fue negociada, discutida y legitimada por otros actores de representación, tanto políticos como sociales. Para el fVs no fue, sin embargo, un error. Kirchner mismo señalaba que esas decisiones de gran contenido antipopular, en específico en cuanto a la suspensión de los salarios atrasados, se habían tomado en "absoluta soledad". ${ }^{16}$ Para la organización no era un déficit sino un símbolo de autoridad y de capacidad de representación de lo que se interpretaba como los intereses de los santacruceños. La siguiente ilustración muestra esa imagen de "autoridad".

14 Los detalles sobre esta medida pueden encontrarse en el capítulo tres de Sosa (2014).

15 Véase, El gobierno anuncia bonificación especial para el personal docente y de sanidad. (1992, 28 de julio). La Opinión Austral; Bonificación por presentismo. Detalles sobre su aplicación. (1992, 6 de agosto). La Opinión Austral; Bonificación especial. Crítica de diversos sectores. (1992, 29 de julio). La Opinión Austral.

16 En la sesión inaugural de la Cámara de Diputados provincial del 1 de mayo de 1992, Kirchner señalaba: "Esto se logró con varias medidas; algunas de ellas muy duras, es cierto. Debo reconocer, en lo personal, que no fue fácil adoptar algunas decisiones y que lo he hecho en la más absoluta de las soledades, pero también con la serenidad que me dio el hecho concreto de que nadie, absolutamente nadie en términos individuales y menos aún sectoriales, propuso otra alternativa para retomar el control de las finanzas provinciales y garantizar el mínimo funcionamiento del Estado" (Diario de sesiones parlamentarias, 1992: p. 10). 


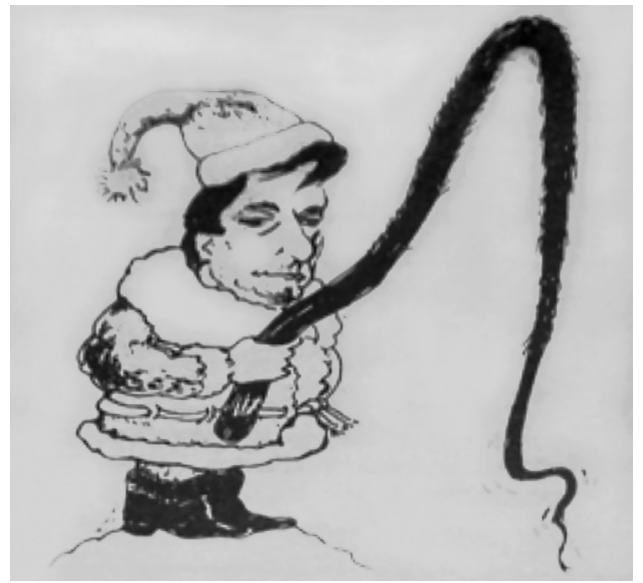

Fuente: La Opinión Austral (1993, 23 de septiembre).

Aunque la crisis, los recortes y ajustes eran moneda corriente en esta coyuntura nacional, la actuación y la forma de afrontar el estado de crisis, las medidas adoptadas por el Fvs y la legitimación de estas, en contraste con anteriores gestiones y con otros gobiernos provinciales, tenían una particularidad: venían acompañadas de un componente vigoroso de demostración de autoridad, de capacidad de control y de disciplinamiento. A modo de ejemplo, la declaración previa de estado de emergencia económica provincial en Santa Cruz, hecha por el gobierno de Ricardo del Val, se había basado en declarar garantías para los derechos laborales que no se estaban cumpliendo por los retrasos y deudas en las transferencias del gobierno federal a las provincias, ${ }^{17}$ mientras que la Ley de Emergencia Económica aplicada por el Fvs fue acompañada por la aprobación de un Decreto de Necesidad y Urgencia que implicaba la suspensión de los regímenes de protección y distribución salarial, entre los que se encontraba la suspensión de las convenciones colectivas de trabajo. ${ }^{18}$ Bajo el gobierno del Fvs, la Ley de Emergencia Económica se orientaba ya no a prestar garantías legales a los derechos que, producto de los atrasos económicos en las transferencias federales, imposibilitaban su sostenimiento, sino a congelar las luchas por

17 Véase, Diario de sesiones parlamentarias sobre la Ley de Emergencia Económica del 31 de mayo de 1989 y Ley Nº 2077 de Emergencia Económica Provincial de junio del mismo año.

18 Para obtener más detalles sobre las especificidades de estas leyes y decretos puede consultarse el capítulo tres de Sosa (2014). 
el poder adquisitivo de los salarios y así apaciguar el conflicto interno. A partir de su irrupción en la política provincial, la responsabilidad y la resolución de la crisis ya no involucraba a la nación y a sus deudas sociales, sino que debía ser resuelta y asumida por los santacruceños. ${ }^{19}$ Este giro fue central. A partir de allí el nuevo gobierno comenzó a construir una imagen de poder en la que el orden podía y debía ser establecido hacia adentro y a través de lo que se comprendía, en ese entonces, como la recomposición del principio de "autoridad" interno. En comparación con el gobierno de Ricardo del Val —a quien se le había sido destituido en 1989 por juicio político, en el marco de una situación definida como de "caos"-, esta organización había elegido un curso de acción particular y diferente. ${ }^{20}$

Esa forma de afrontar la crisis por parte del fvs también se hace visible cuando se compara con lo hecho por otros gobiernos provinciales afectados, asimismo, por las deudas que la nación tenía con las provincias, un denominador común en buena parte de estas entre fines de 1980 y comienzos de la década de 1990. La antítesis de la estrategia adoptada por Kirchner en Santa Cruz fue la que se usó en Río Negro. Horacio Masaccessi, reelecto gobernador en esa provincia por el radicalismo en 1991, tomó de las arcas de Banco Nación en General Roca, capital de la provincia, dieciséis millones de dólares argumentando que eran parte de la deuda del gobierno nacional con esta provincia. ${ }^{21}$ En una actitud que fue interpretada como de Robin Hood (Micro Semanario, 1991: p. 3), Masaccessi, catalogado como el Menem rubio - por su relativa simpatía con la política del entonces presidente- emitió un decreto ley, se apoderó de fondos federales guardados en una caja de seguridad en el Banco de Río Negro y pagó los sueldos de 35000 empleados públicos, acción que lo puso al borde del juicio político y le implicó una causa penal que hasta la actualidad no está resuelta (Micro Semanario, 1991: s. p.). Si bien replicaba el esquema de toma de decisiones de Kirchner en Santa Cruz, ya que el ajuste se determinó sin el diálogo con otros actores de representación de intereses (la legislatura provincial nunca aprobó la medida), Masaccessi orientaba sus acciones a partir de la

19 Véase, Kirchner: "La sociedad santacruceña debe asumir la realidad. (1992, 9 de enero). La Opinión Austral.

20 Esta política de disciplinamiento interno debe comprenderse en el marco de las relaciones del gobierno provincial con el nacional que lideraba Carlos Menem. El ministro de Economía, Domingo Cavallo, introdujo políticas que reducían los gastos de las provincias. Por otro lado, las deudas que la nación tenía con las provincias quedaban supeditadas formal e informalmente al alineamiento político de ellas y al cumplimiento de metas fiscales de reducción de presupuestos. En este sentido, las políticas de disciplinamiento en pos del equilibrio de las cuentas públicas era parte de una estrategia del gobierno peronista que excedía los límites de la provincia de Santa Cruz.

21 Véase, Piden procesamiento del gobernador de Río Negro. (1991, 12 de julio). La Opinión Austral. 
interpretación de que tanto el origen como la resolución de la crisis obedecía a los vínculos económicos con la nación. ${ }^{22}$

En Santiago del Estero, el gobierno de Carlos Mujica, quien provenía de las líneas del juarismo —expresión principal del pj local—, para 1993 mantenía tres meses de atraso salarial y estaba completamente debilitado. Este gobierno quedó sujeto a la aprobación de la Ley Ómnibus —un paquete de medidas de ajuste fiscal impulsado por Domingo Cavallo, ministro de Economía de Carlos Menem, para disminuir el gasto en las provincias - a cambio de obtener fondos federales para solventar su crisis. La debilidad del gobierno provincial y la intervención del nacional eran tales que en la sesión de aprobación de esa ley asistieron técnicos del Ministerio de Economía a defender el ajuste local, y en esa jornada estalló el santiagueñazo, un levantamiento popular contra los tres poderes del Estado (Farinetti, 2013). Posteriormente, la intervención, frente al levantamiento, regularizó la situación económica. Las medidas ante la crisis en Santiago del Estero no fueron acompañadas ni por la pretensión de algún tipo de autoridad ni se impulsaron — aún en una provincia calificada como "fuertemente informal" y "autoritaria”- por fuera de algún tipo de instancia de mediación política, en este caso, la vía parlamentaria. ${ }^{23}$

En la provincia de Buenos Aires, Eduardo Duhalde, dirigente del pJ, antes de asumir el gobierno contaba con la aprobación de las leyes esenciales que le permitieron tomar las medidas de reforma. A días de tomar el poder impulsó y logró la aprobación de la ley de reconversión administrativa, la cual pretendía una mayor efectividad y eficacia descentralizando las "burocracias enquistadas" y erradicando la corrupción de estas, para poner en disponibilidad trescientos mil trabajadores públicos dependientes de la provincia, una de las medidas de ajuste más importantes (Erbetta, 2011). ${ }^{24}$

En San Juan Jorge Escobar, el gobernador electo en 1991 y proveniente del PJ, contaba al momento de su asunción con un marco legal aprobado por

22 No contamos con datos precisos que permitan observar qué limitaciones implicó al gobierno de Río Negro seguir una acción contraria a los intereses y políticas seguidas por el gobierno nacional de disciplinamiento fiscal y reducción del gasto.

23 El caso de Santiago del Estero abona a la hipótesis de que la filosofía política que acompañó las medidas de estabilización en Santa Cruz era afín con lo que más adelante se describe en este artículo como la cultura del sufrimiento. La ausencia de un estallido político en Santa Cruz no se explica directamente por la menor profundidad de su crisis, sino por su menor disposición a la movilización, relacionada con esa cultura del sufrimiento.

24 La intensidad del ajuste en Buenos Aires fue relativizado por el Fondo de Reparación Histórica del Conurbano Bonaerense, el área de mayor concentración poblacional de esta provincia. Este fondo menguó ampliamente el impacto de las reformas. La importancia cuantitativa en el presupuesto provincial, desde su creación en el contexto de ajuste, fue la fuente de mayor peso de intervenciones sociales en esa área geográfica (Danani, Chiara \& Filc, 1997). 
la legislatura provincial, conformado por la Ley Ómnibus y otras leyes. Este paquete le permitió llevar adelante las reformas y el ajuste a esta provincia, aunque la justificación tuvo un perfil estrictamente tecnocrático y academicista. Para sustentar los cambios que desataron los hechos que terminaron en el juicio político que lo destituyó, se organizó junto al Instituto Nacional de Administración Pública (INAP) y la Universidad Nacional de San Juan (UNSJ) el Segundo Seminario Nacional sobre Reforma del Estado en mayo de 1992 (Rodrigo, 2013). Este tipo de eventos políticos formaban parte de la estrategia de construcción de la imagen de un gobierno que no se presentaba ante la sociedad, como el gobierno del Fvs, para "restaurar el orden", sino para construir definitivamente un Estado "racional y eficiente".

Algunos puntos de convergencia y divergencia con la estrategia del gobierno nacional de Carlos Menem permiten visualizar algunas particularidades del gobierno del fvs. No debe inferirse con esta afirmación que este último no haya recurrido a las estrategias de legitimación propias del discurso tecnocrático y de perfil neoliberal que se implementaban entonces a nivel nacional. ${ }^{25} \mathrm{La}$ generación de orden y equilibrio no fue una política aplicada solo en Santa Cruz; recomponer la autoridad gubernamental era una política que atravesaba a todo el cuerpo peronista. Lo particular del caso santacruceño, y que lo diferencia de otros provinciales y del nacional, es la forma de recomponer la autoridad. Las medidas aplicadas en Santa Cruz se realizaron sin mediación política e interrelación con otros actores y esta forma de intervención se defendió e interpretó como evidencia de la capacidad de ejercer la autoridad.

25 Un tipo de legitimidad típica de las organizaciones políticas es la posesión y reivindicación, por parte de sus referentes fundamentales, de cualidades que expresen éxito en las actividades sociales más valoradas (Lagroyé, 1994: p. 244). Esta fuente de legitimación fue central para el Fvs. En su búsqueda de diferenciación política, no solo respecto del pu sino también del resto de las fuerzas opositoras, desplegó un mecanismo de legitimidad basado en la reivindicación de capacidades técnicas y de gestión como atributo propio, el cual se reflejaba en las credenciales profesionales de sus principales referentes y se afirmaba en las estrategias de campaña y los discursos de sus representantes. Una mezcla de valores como eficiencia, administración, planificación, cumplimiento de objetivos concretos y compromiso con el trabajo, se fueron expresando de diversas formas en las acciones de esta nueva fuerza política. El primer cargo que ocupó Cristina Fernández de Kirchner (presidenta de la Nación, 2007-2015) fue el de coordinadora del Consejo de Planeamiento, Asesoramiento y Consulta, en la intendencia de Río Gallegos, capital de Santa Cruz, en 1987, puesto que compartió Julio De Vido (ministro de Planificación de la Nación, 20032015), quien cumplía funciones de asesor. En esa experiencia de gobierno, también se creó la Secretaría de Planeamiento, que ocupó Alicia Kirchner (ministra de Desarrollo Social de la Nación, 2003-2015), con credenciales universitarias necesarias para coordinar el área social. Las nuevas carteras que expresaban estos nuevos valores y el ascenso de una nueva élite también se manifestó en los discursos políticos con los que el Fvs se posicionaba en el espacio político. Sin embargo, el fvs no utilizó estas credenciales para justificar las formas de construcción de orden y autoridad. La legitimidad de estas medidas se basó — como parte de la construcción del liderazgo de Kirchner- en soportar los "costos" políticos de un conjunto de medidas que carecieron de cualquier tipo de consenso y negociación. 
Efectivamente, el contraste con el ámbito nacional abona a dicha hipótesis Incluso en un contexto de urgencia y crisis, como el que se expresó con la hiperinflación de aquel momento, el gobierno electo por el pJ nacional aceptó el traspaso adelantado del mando presidencial — previo acuerdo con el ex presidente de la república, Raúl Alfonsín-, y las reformas económicas y estructurales de su gobierno fueron votadas por el Congreso Nacional, aun cuando suponían grandes niveles de discrecionalidad en su aplicación. Por supuesto que la mayoría de los dirigentes políticos, en especial los nucleados en el pJ, buscaron construir imágenes vinculadas a su capacidad de gobierno de las crisis. Como ha señalado Novaro (1994), buena parte de ellos carecían de trayectorias y capitales políticos y se legitimaron sorteando las crisis que afectaban a las provincias. Sin embargo, la categorización de "pilotos de tormenta", como se autodefinieron Menem (presidente de la nación) y Duhalde (gobernador de la provincia de Buenos Aires), para reivindicar sus atributos políticos, no sería la más adecuada para Kirchner. La idea de comandar el barco se desajusta si se toma en cuenta que la autoridad implicó la suspensión de canales de diálogo, algo bastante atípico en el universo peronista, rasgo que podía estar relativamente presente en otros territorios provinciales, pero que en el caso de Santa Cruz se acentuaba y se veía como el atributo de un liderazgo que indicaba fortaleza y capacidad de gobierno.

La impronta de la imposición de disciplina, autoridad y orden, que implicó acciones radicales, consistentes y fuera de cualquier canal de negociación y de consenso acercó a Kirchner mucho más a la figura de Cavallo, quien, en pos de sus convicciones, arremetía fuertemente en las provincias con el discurso de la extrema disciplina fiscal y, en consecuencia, social. Además de las simpatías y la buena relación que por entonces Kirchner tenía con aquel dirigente, por esos años era considerado en medios periodísticos afines a la política del $\mathrm{Mi}$ nisterio de Economía, como producto de la disciplina y reordenamiento que había aplicado hacia adentro de su territorio, como un discípulo de Cavallo. En diciembre de 1991, en una nota sobre la asunción de Kirchner como gobernador, Ámbito Financiero, periódico de noticias económicas y políticas de alcance nacional, titulaba: "Juró otro seguidor de Cavallo. Néstor Kirchner no recuerda peor momento en la vida de Santa Cruz" (Ámbito Financiero, 11/12/1991: p. 12). Y luego de que el nuevo gobernador aplicara las primeras medidas, aludiendo a estas, dicho diario titulaba "Kirchner sí cumple" (Ámbito Financiero, 16/12/1991: p.15), evidenciando la afinidad entre la exigencia de disciplina interna que demandaba el Ministerio de Economía a todas las provincias y la política que el fvs comenzaba a aplicar en Santa Cruz, pese a las diferencias entre las políticas neoliberales aplicadas bajo el gobierno de Carlos Menem y la política que tuvo el Fvs en relación al Estado. Sin embargo, las formas de gestionar de ambos actores resaltan sus distintos modos de construir autoridad. 
A diferencia de Kirchner, Cavallo, quien desde 1991 impulsó todas las reformas a nivel nacional, no utilizó decretos. Sus más importantes medidas, especialmente las privatizaciones, fueron votadas en el Parlamento y establecidas por ley, lo que es distinto de la solitaria toma de decisiones de Kirchner en Santa Cruz.

Finalmente, la aplicación y el éxito de las medidas orientadas al reordenamiento interno de la provincia y el ingreso en un periodo fiscal favorable, dado básicamente por la reactivación de los flujos económicos federales a la provincia, el pago de las deudas atrasadas y los beneficios de la estabilidad derivados de la Ley de Convertibilidad —el régimen de paridad cambiaria entre pesos y dólares que rigió durante toda la década de 1990- fueron condiciones que permitieron el periodo de estabilidad que, como se verá en el apartado siguiente, tuvieron a su vez un contexto que las posibilitaron. Hacia fines de 1992, Santa Cruz se encontraba en una situación de estabilidad financiera y social. En menos de un año, el gobierno provincial cumplía con su promesa y restablecía el 10 y el 15\% que meses antes había descontado a los empleados de la Administración Pública Provincial (APP), además del sueldo de diciembre y el medio aguinaldo del decreto 309. Los fondos por regalías mal liquidadas - previo apoyo, por parte del gobierno, de la privatización de YPF-, los ingresos generados por el pacto fiscal federal y la regularización de los pagos sobre la coparticipación ante el cese de la inflación, ingresos que se generaron durante 1992, permitieron la recomposición económica y el comienzo de la holgura financiera de una provincia chica y petrolera. ${ }^{26}$ Sin embargo, la estabilidad social y política no fue atribuida ni a esta nueva relación económica entre nación y provincia, ni al ingreso de una etapa de estabilidad generada por el sistema de convertibilidad, sino a la capacidad de gobernar de Kirchner. El Fvs había ganado su primera batalla política por la representación: había "prometido" orden y había "logrado" orden.

\section{Sobre los orígenes de la legitimidad del "orden" para los santacruceños}

¿Qué explica que el orden y las formas de lograrlo hayan sido concepciones legítimas para esa sociedad? ¿Por qué ese tipo de construcción de autoridad fue efectivo y representativo para la misma? En este apartado mostraremos que ello se debe por lo menos a dos condiciones. En primer lugar, al debilitamiento de otros actores de representación, como los partidos y las organizaciones gremiales. En segundo, porque el discurso del orden expresaba los intereses de los grupos

26 Véase, Incremento salarial para estatales. (1992, 15 de agosto). La Opinión Austral; Reintegrarán descuentos a los empleados públicos. (1992, 23 de octubre). La Opinión Austral. 
sociales predominantes de la historia de Santa Cruz, un orden cuyo arraigo he definido en otras investigaciones como "cultura del sufrimiento".

Para comprender el éxito del fvs en el establecimiento del orden, en tanto nuevo principio de representación, se debe reconstruir el debilitamiento de los actores que conformaban el sistema de acción de la provincia y sus consecuencias para la lucha política, en tanto imposición de visiones del mundo social (Bourdieu, 1981, 1993). Efectivamente, a diferencia de lo que sucedió en otras provincias, las protestas sociales en Santa Cruz ante las medidas de ajuste y las de privatización nacional fueron poco significativas. No hubo en Santa Cruz ni protestas vinculadas a la efervescencia social como la de Santiago del Estero ante la reducción y la crisis de la APP (Farinetti, 2002; Sosa, 2014), ni estrategias de protestas más orgánicas como la conformación de un movimiento de desocupados como la que se dio en provincias fuertemente afectadas por la privatización de las empresas estatales (Svampa \& Pereyra, 2003; Sosa, 2014). Los trabajos sobre los conflictos sociales en Santa Cruz hacia fines de la década de 1980 y la aplicación de las medidas llevadas a cabo por el Fvs muestran que estas tuvieron, sin mayores resistencias, los impactos estabilizadores que pretendían (Luque, Martínez, Auzoberría \& Huenul, 2003). Pese a la fuerte presencia del Estado en la dinámica social, las medidas de ajuste, reforma y privatización no generaron procesos sociales efervescentes u orgánicos significativos como respuesta. La libertad que tuvo el gobierno provincial para actuar de manera directa, sin recurrir a instancias o actores que expresaran vínculos de representación y mediación entre la política y la sociedad, le permitió abonar a su imagen de autoridad, basada en el establecimiento del orden, que fue un componente central del capital político que construyó luego de llegar al gobierno.

Ahora bien, para entender la legitimidad del discurso del orden a nivel provincial, debemos esclarecer su relación con los valores de los grupos dominantes locales. Durante el siglo xx, hubo en Santa Cruz tres grupos dominantes que, dadas sus posiciones de privilegio y centralidad, fueron moldeando una ideología local plasmada en los atributos de la cultura de esta provincia y funcionando como un mecanismo de construcción de jerarquías internas: los denominados "Nacidos y Criados", los militares y los hombres. El primer grupo constituyó una categoría social construida en oposición a "los de afuera" o los "recién llegados" a la provincia, la cual se ha conformado de afluentes de migrantes permanentes que reivindicaban los valores de los "pioneros", esto es, aquellos que habían poblado la Patagonia a principios del siglo xx. Esta categoría, consolidada a mediados de dicho siglo, defendía posiciones de privilegio social reivindicando su "tiempo de residencia" en el lugar que, en un espacio social caracterizado por el aislamiento, el frío y condiciones sociales, culturales y económicas adversas, implicaba una "mayor tolerancia al sufrimiento", símbolo de 
"capacidad de resistencia" y "tolerancia a la adversidad" que los dotaba de cierta superioridad moral. Unas declaraciones de Kirchner en el contexto de aplicación de las medidas revelan cómo el estereotipo de los pioneros, paradigma de la "cultura del sufrimiento", se conformó en el discurso específico acerca de la construcción del "orden":

En lo personal debo confesar que me resultó más que difícil tomar esta decisión. Pero sinceramente es la única que visibilizo como posible para afrontar esta situación de carácter terminal [...] Santacruceńos, estoy seguro que vamos a poder afrontar esta crisis. Pero no les voy a mentir. Va a costar y mucho salir de ella. Esfuerzo, sacrificio, tiempo y en algunos casos hasta dolor. Van a caer privilegios y todos tendremos algo que resignar, porque ya nadie podrá pretender, como ha sido hasta ahora, salvarse mientras otros no tienen siquiera la esperanza de un futuro mejor. He nacido en esta tierra. Todo lo que tengo lo tengo plantado en mi provincia y no estoy dispuesto a bajar los brazos. Por eso recurro una vez más al ejemplo de los que nos antecedieron. Al ejemplo de los pioneros que vinieron a Santa Cruz, cuando no había gas, ni pavimento, ni planes de vivienda, ni obra social, ni presupuesto provincial que les permitiera por magro que fuera un ingreso fijo. Vinieron y nos dejaron todo sin pedir nada. Es responsabilidad nuestra, entonces, convertirnos como ellos en bisagras de la historia, y ser pioneros de un Estado moderno, de una Santa Cruz diferente. Para que su sacrificio no haya sido en vano. Ruego a Dios que me dé y nos dé a todos la fuerza que necesitamos para construir ese futuro que seguramente llegará (El gobernador habló anoche al pueblo de la provincia, 1992, 7 de enero, Nota de Tapa).

La reivindicación del "sacrificio", el llamado a la "disciplina y al esfuerzo", la idea de la "entrega total" a cambio de nada eran valores fuertemente afines a otro grupo de importante presencia en Santa Cruz: la institución militar. El desembarco de lo que Bohoslavsky (2009) ha denominado "proyecto nacionalista" en Santa Cruz tuvo fuertes impactos en la configuración social del territorio en general y en los lazos sociales en particular. En este proyecto había dos objetivos centrales del Estado nacional: la defensa de la soberanía y el desarrollo de la autonomía energética. La consolidación de Santa Cruz como área privilegiada para la defensa de la soberanía, en tanto componente central del "proyecto nacionalista" tuvo dos pilares fundamentales. Por un lado, la conformación y el desarrollo de asentamientos militares y, por otro, la regular recreación de la hipótesis de conflicto bélico con otros países en distintas etapas. En el contexto patagónico, considerado el eslabón débil de la soberanía nacional (Bohoslavsky, 2008), Santa Cruz fue un centro neurálgico y militarmente estratégico tanto en las distintas hipótesis de conflicto, especialmente con Chile en 1978 cuan- 
do Argentina ensayó un Estado de guerra ${ }^{27}$ debido a las disputas por el Beagle, y con Inglaterra en la guerra de Malvinas. Pese a que los conflictos afectaron toda el área patagónica, fuertemente atravesada por la matriz militar, la posición geográfica de Santa Cruz la constituyó en un eslabón militar central en los hipotéticos y reales conflictos bélicos. Durante la última dictadura militar, toda la región patagónica fue un territorio de alto interés para la Armada, que avanzó progresivamente en su control. Al mismo tiempo, Santa Cruz fue una de las pocas provincias que permaneció bajo control de gobernadores militares, en este caso, de la Fuerza Aérea, durante toda la dictadura, sin ser gobernada nunca por civiles (Canelo, 2013). Las instituciones militares en Santa Cruz durante todo el siglo xx explica la presencia de la matriz discursiva del disciplinamiento que acompañó las formas particulares y los sentidos de construir "orden" en el territorio. Es muy probable que lo militar haya impregnado tanto los valores propios de la cultura local como los valores políticos y puede considerarse un afluente de la conformación de "la cultura del sufrimiento".

Gráfica 1. Evolución del índice de masculinidad. 1985-2001. Santa Cruz, Santa Fe y promedio nacional

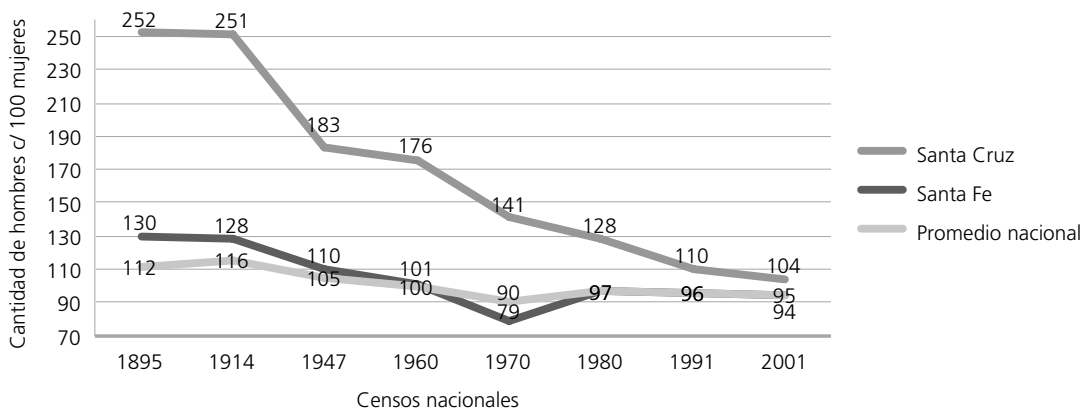

Fuente: Elaboración propia con datos de INDEC, Ministerio de Economía de la provincia de Buenos Aires, Cuadra (2000) y Carbonetti, Peretti \& Tarabella (S/N).

Finalmente, un tercer grupo influyó en el perfil adquirido por la cultura local: los hombres. La importancia porcentual de los hombres respecto de las mujeres ayuda a comprender otra dimensión de la "cultura del sufrimiento": la reivindicación permanente de la "fortaleza física y espiritual" y el "coraje" como símbolos de superioridad, valores afines a las representaciones de la masculinidad (Palermo, 2015). La gráfica 1 muestra la presencia exacerbada de los hombres

27 La intervención de Juan Pablo II evitó por cuestión de horas el inicio de las hostilidades (Lafuente, 1986: p. 87). 
en relación con las mujeres en Santa Cruz en comparación con otros distritos y capta la importancia del género masculino en la composición santacruceña en la historia social del siglo xx.

Este último aspecto de la identidad local consolidó la representación de la sociedad de "hombres fuertes" que formó parte de la creencia en las facultades extraordinarias, atributo más destacado del carisma de Kirchner. Una forma de representar este rasgo fue recurrir a las declaraciones que resaltaban el coraje o la firmeza personal para conducir la sociedad como cuando sostuvo, al tiempo de asumir, que había "llegado un santacruceño viril para defender los intereses de la provincia y de su pueblo" (La Opinión Austral, 1992: p. 1) o cuando señalaba que "había tomado las peores decisiones en absoluta soledad" (Diario de sesiones parlamentarias, 1992: p. 10).

Por último, la trayectoria de los dirigentes del fvs expresa otro dato que indica por qué esta organización encarnó estos valores sociales dominantes. Esta fuerza política, por entonces en ascenso en Santa Cruz, poseía los rasgos de una élite sin capital social. En términos generales, excepto Néstor Kirchner y Alicia Kirchner (ministra de Desarrollo Social de la Nación, 2003-2015), hermana de este dirigente y ministra de Desarrollo Social de Santa Cruz durante la década de 1990, la élite del Fvs se integraba de migrantes internos recién llegados, carentes de capital político y social. Para estos recién llegados y para los de escaso capital político — y, en muchos casos, social—, representar los valores de los que se "habían cagado más de frío" - frase que localmente referencia a tolerar el sufrimiento- era una estrategia de interpelación para legitimarse al interior de una provincia que hacía de ese atributo uno de sus valores principales y parte de su identidad. Encarnar y representar los valores de los que habían sufrido más (producto de generaciones atravesadas por el frío) fue la estrategia más adecuada para posicionarse ante esa sociedad. ${ }^{28}$

Esta diferencia de atributos internos de la fuerza, basada en la trayectoria migratoria, es central para comprender no solo el lugar de superioridad que adquirió Kirchner en la organización, sino también la predisposición al trabajo y a la obediencia de los miembros principales que hacían de la "militancia" su valor esencial. Probablemente la "cultura del sufrimiento", encarnada tanto en el espíritu y discurso de los pioneros como en los militares, en tanto valores diferenciadores de la sociedad santacruceña, influyó en las acciones y en la obediencia interna del grupo de los mandatarios en general, pero con mucha más fuerza en los que no habían nacido en la provincia o que habían arribado a ella recientemente. Representar a una sociedad que hacía de la capacidad de

28 Sobre la relación entre estos valores dominantes, encarnados por el gobierno del Fvs y el perfil "militante" de esta organización, véase, Sosa (2014). 
sufrimiento y de renuncia un valor y mostraba una fuerte predisposición social a la adversidad, que cobrara cada vez más peso en un contexto en el que los impactos de la desintegración social revelaban un panorama social cada vez más hostil, implicaba, y más radicalmente para los "recién llegados", que estaban obligados a demostrar más la posesión de esos valores.

La afinidad entre el discurso del nuevo gobierno y la cultura del sufrimiento es tal vez la variable que abre pauta para comprender las diferencias entre los principios de autoridad y de representación que se pusieron en juego en el contexto de las reformas a nivel nacional, en Santa Cruz y en otras provincias. La representación de los valores de los grupos dominantes locales, fuertemente presentes en los imaginarios locales y sus formas de identificación, permite comprender por qué un conjunto de medidas de ajuste económico radical aplicadas sin considerar ningún canal de negociación o de búsqueda de consenso puede ser considerada legítima por una sociedad. La dureza de las medidas y de las formas de aplicación denotaba un gobierno que representaba los valores de una sociedad de hombres "fuertes", "disciplinados", con "coraje" y con una gran capacidad de "resistencia" y "tolerancia a la adversidad".

\section{Conclusión}

En este artículo se ha mostrado una de las estrategias de representación del Fvs en Santa Cruz que legitimó el liderazgo de Néstor Kirchner, y la consolidación de esa fuerza y de su dirigente fundamental como garantías del orden y la estabilidad. Al comenzar la década de 1990, el gobierno de Kirchner llegó al poder con un escaso caudal de votos y en un contexto en el que los partidos ya no garantizaban la legitimidad a sus representantes. En este marco, una primera estrategia de diferenciación de la nueva fuerza se basó, sobre todo en su primera etapa de gobierno entre 1991 y 1995, en "recomponer el principio de autoridad en una sociedad subsumida en la anarquía".

En segundo lugar, se han expuesto las medidas con las que se construyó el "orden" a nivel local y las formas en las que se implementaron buscando erigir una imagen de autoridad. Como se pudo apreciar, ello no sucedió de cualquier manera, contrariamente, se realizó por fuera de las instituciones y los actores de representación: parlamentarias, políticas y gremiales. En Santa Cruz demostrar poder de autoridad implicó decidir de manera autónoma prescindiendo de los consensos con todo actor de representación. Estar fuera de los canales de negociación acentuó la imagen de autoridad del nuevo gobierno y de su representante fundamental: Néstor Kirchner. 
En tercer lugar, se han reconstruido las condiciones sociales y culturales que hicieron que este modo de instituir el "orden" fuera legítimo y reconocido como un valor para la sociedad. La afinidad entre el discurso del nuevo gobierno y la cultura del sufrimiento - hecha de los valores e imaginarios de los grupos sociales predominantes en esta provincia - es probablemente la variable que lleva a comprender las diferencias entre los principios de autoridad y de representación puestos en juego en el contexto de las reformas a nivel nacional, en el caso particular de Santa Cruz y en otras provincias. Ello permite entender por qué medidas de ajuste económico radical aplicadas sin negociación o de búsqueda de consenso pueden constituir el origen del poder carismático de un dirigente político.

\section{Referencias}

Abal Medina, J. M. (2004). La muerte y la resurrección de la representación política. Buenos Aires: Fondo de Cultura Económica.

Aboy Carlés, G. (2005). Populismo y democracia en la Argentina contemporánea. Entre el hegemonismo y la refundación. Estudios Sociales, XV (28), 125-149.

Bohoslavsky, E. (2009). El complot patagónico. Nación, conspiracionismo y violencia en el sur de Argentina y Chile (siglos XIX y XX). Buenos Aires: Prometeo.

Bohoslavsky, E. (2008). La Patagonia: (de la guerra de las Malvinas al final de la familia ypefiana). Buenos Aires: Universidad Nacional de General Sarmiento/Los Polvorines.

Bosoer, F. \& Leiras, S. (1999). Posguerra fría, "decisionismo", neodecisionismo y nueva fase del capitalismo. En Borón, A., Gambina, J. \& Minsburg, N. (Comps.). Tiempos violentos. Neoliberalismo, globalización y desigualdad en América Latina (S/R). Buenos Aires, Clacso/ Eudeba.

Bourdieu, P. (1993). La delegación y el fetichismo político. En Cosas dichas (pp. 45-67). Barcelona: Gedisa.

Bourdieu, P. (1981). La representación política. Elementos para una teoría del campo político. Actas de Investigación en Ciencias Sociales, (64), pp. 5-19.

Canelo, P. (2011). Son palabras de Perón. Continuidades y rupturas discursivas entre peronismo y menemismo. En Pucciarelli, A. (Coord.). Los años de Menem. La construcción del orden neoliberal (pp. 71-111). Buenos Aires: Siglo XXI. 
Canelo, P. (2013). Construyendo elites dirigentes. Los gobernadores provinciales durante la última dictadura militar (Argentina, 1976-1983). Anuario del Centro de Estudios Históricos "Prof. Carlos S. A. Segreti", 11(11), pp. 323-341.

Carbonetti, A. Peretti, G. \& Tarabella, L. (S/R). Aproximaciones al estudio del proceso de envejecimiento y feminización de la población en la provincia de Santa Fe a partir de la Segunda mitad del siglo XX. Recuperado el 30 de agosto de 2017, de http://www.redaepa.org.ar/ jornadas/xjornadas/papers/pdf/76.pdf

Cheresky, I. \& Pousadela, I. (2004). El voto liberado. Elecciones 2003: perspectiva histórica y estudio de casos. Buenos Aires: Biblos.

Danani, C., Chiara, M. \& Filc, J. (1997). El fondo de reparación histórica del Conurbano Bonaerense: una aproximación macroinstitucional. Buenos Aires: UNGS.

Erbetta, C. (2011). La reconversión del estado durante la primera gobernación de Duhalde en la provincia de Buenos Aires. Trabajo y Sociedad, (16), pp. 287-298.

Fabbrini, S. (2009). El ascenso del Príncipe democrático. Quién gobierna y cómo se gobiernan las democracias. Buenos Aires: Fondo de Cultura Económica.

Farinetti, M. (2013). La trama del Juarismo: politica y dominación en Santiago del Estero 19832004. Tesis de doctorado en Ciencias Sociales. FSOC-UBA.

Farinetti, M. (2002). La conflictividad social después del movimiento obrero. Nueva Sociedad, (182), 60-75.

Gaxie, D. (2004). La Democracia Representativa. Santiago: Lom Ediciones.

Isla, A. (2000). Los apoyos a Bussi. Valores domésticos, espacios públicos en el presente tucumano. En Svampa, M. (Ed.). Desde abajo: la transformación de las identidades sociales (S/R). Buenos Aires: Biblos.

INDEC. Censos históricos de Población. 1914, 1947, 1960, 1970, 1980,1991, 2010.

Lafuente, H. (2007). Historia politica de Santa Cruz (1912-1958). Buenos Aires: Kaikén.

Lagroyé, J. (1994). Sociología politica. Buenos Aires: Fondo de Cultura Económica.

Lascurain, M. C. (2011). Cambios en la representación política. Un abordaje a partir de los perfiles de los gobernadores peronistas de la provincia de Santa Fe entre 1983 y 2007. Papeles de Trabajo, 5(8), pp. 117-133. 
Luque, E., Martínez, Auzoberría, S. \& Huenul, M. (2003). Conflictos Sociales en la provincia de Santa Cruz. Los ańos noventa. En PIMSA, pp. 24-48.

Mauro, S. (2007). Mutación, crisis, recomposición, y otra vez crisis de la representación política en la Ciudad de Buenos Aires. Los avatares del signo Progresista. Argumentos. Revista de Crítica Social, (8), pp. 1-21.

Ministerio de Economía de la provincia de Bs. As. (S/R). Análisis de la población de la provincia de Bs. Aires en función de su estructura por sexo y edad. Recuperado el 30 de agosto de 2017, de www.ec.gba.gov.ar

Novaro, M. (2011). La cultura política y el sentido común bajo el kirchnerismo. En Malamud, A. \& Luca, M. de (Comps.). La politica en tiempos de los Kirchner (pp. 129-140). Buenos Aires: Eudeba.

Novaro, M. (1994). Pilotos de tormentas: crisis de representación y personalización de la politica en Argentina (1989-1993). Buenos Aires: Letra Buena.

O’Donnell, G. (1997). Contrapuntos. Ensayos escogidos sobre autoritarismo y democratización. Buenos Aires: Paidós.

Offerlé, M. (2004). Los partidos políticos. Santiago: LOM Ediciones.

Palermo, H. (2015). Machos que se la bancan: masculinidad y disciplina fabril en la industria petrolera argentina. Desacatos. Revista de Antropología Social, (47). Recuperado el 30 de agosto de 2017, de http://desacatos.ciesas.edu.mx/index.php/Desacatos/article/view/1424

Pucciarelli, A. (2002). La democracia que tenemos. Declinación económica, decadencia social y degradación politica en la Argentina actual. Buenos Aires: Libros del Rojas.

Quiroga, H. (2005). La Argentina en emergencia permanente. Buenos Aires: Edhasa.

Rinesi, E. (2007). Representatividad, legitimidad, hegemonía. Los dilemas de la representación política después del desbarajuste. En Emiliozzi, S., Pecheny, M. \& Unzué, M. (Comps.). La dinámica de la democracia. Representación, instituciones y ciudadania en Argentina (pp.111136). Buenos Aires: Prometeo.

Rinesi, E., Vommaro, G. \& Muraca, M. (Comps.). (2010). Si éste no es el pueblo. Hegemonía, populismo y democracia en Argentina. Buenos Aires: Los Polvorines/Universidad Nacional de General Sarmiento/Instituto de Estudios y Capacitación/Federación Nacional de Docentes Universitarios. 
Rivas, A. (2004). Gobernar la educación: estudio comparado sobre el poder y la educación en las provincias argentinas. Buenos Aires: Ediciones Granica.

Rodrigo, C. (2013). El Poder en crisis. Relaciones de gobierno e inestabilidad politica en San Juan. Tesis de doctorado en Ciencias Sociales. Buenos Aires: FSOC-UBA.

Sidicaro, R. (2011). Los tres peronismos. Buenos Aires: Siglo XXI.

Sosa, P. (2014). Desintegración social y poder politico. Génesis y consolidación del Frente para la Victoria en la Provincia de Santa Cruz (1988-1996). Tesis de doctorado inédita, FCs-UBA.

Svampa, M. \& Pereyra, S. (2003). Entre la ruta y el barrio. La experiencia de las organizaciones piqueteras. Buenos Aires: Biblos.

Vilaboa, J. \& Bona, A. (2016). La renovación en Santa Cruz, 1983-1991. En Ferrari, M. \& Mellado, V. (Coords.). El peronismo en la historia reciente. Dilemas del momento renovador en clave subnacional (1983-1991) (pp. 241-268). Caseros, EDUNTREF.

Yabkowski, N. (2012). La negación de la parte: La crisis de la representación política argentina. Nómadas. Revista Crítica de Ciencias Sociales y Jurídicas, (Núm. Especial: América Latina). Recuperado el día 30 de agosto de 2017, de http://dx.doi.org/10.5209/rev_NOMA.2012.41784

Recibido el 1 de julio de 2015. Aceptado el 20 de enero de 2017. 